\title{
Seismic Structure and Seismicity in the Southern Mariana Trough and Their Relation to Hydrothermal Activity
}

\author{
Toshinori Sato, Mariko Mizuno, Hiroyoshi Takata, Tomoaki Yamada, Takehi \\ Isse, Kimihiro Mochizuki, Masanao Shinohara, and Nobukazu Seama
}

\begin{abstract}
The Southern Mariana Trough is an active back-arc basin with hydrothermal activity. We investigated relations between the back-arc spreading system and the hydrothermal system in this area by conducting a seismic reflection/refraction survey and a three-month campaign of seismic observations using ocean bottom seismometers. From a 3D seismic velocity structure analysis, we mapped a low-velocity structure just beneath the spreading axis, a high-velocity structure with convex upward beneath an off-axis knoll, and a thickening of layer 2 (to about $3 \mathrm{~km}$ ) over the refraction survey area compared with normal mid-ocean ridges. We found very low seismicity in the hydrothermal area and high seismicity in areas of high topographic relief that probably represent arc volcanoes. The low-velocity structure at the axis suggests that there is some magmatic activity beneath the axis in the form of sheetlike mantle upwellings. These may constitute the hydrothermal heat source at this site. The high-velocity structure with convex upward at the off-axis knoll suggests the presence of off-axis volcanism there. The very low seismicity suggests that this volcanism may have ceased, thus residual heat of this off-axis volcanism may contribute the heat for hydrothermal activity at this site. A comparison of the velocity structure with other back-arc spreading zones and mid-ocean ridges shows that the Southern Mariana Trough has a relatively thick layer 2 with lower seismic velocities, suggesting that the crust was formed by magmas with high volatile contents, consistent with upwelling mantle influenced by subduction. The very low seismicity at the hydrothermal sites indicates that there are no faults or fractures related to the hydrothermal activity. This suggests that the activity is not related to tectonic stresses there.
\end{abstract}

\section{Keywords \\ Back-arc spreading - Crustal structure - Hydrothermal activity - Seismic structure $•$ Southern Mariana Trough}

T. Sato $(\square) \bullet$ M. Mizuno $\bullet$ H. Takata Department of Earth Sciences, Graduate School of Science, Chiba University, 1-33 Yayoi-cho, Inage-ku, Chiba 263-8522, Japan e-mail: satot@earth.s.chiba-u.ac.jp

T. Yamada • T. Isse $\bullet$ K. Mochizuki • M. Shinohara Earthquake Research Institute, University of Tokyo, 1-1-1, Yayoi, Bunkyo-ku, Tokyo 113-0032, Japan

N. Seama

Department of Earth and Planetary Sciences, Kobe University, 1-1 Rokkodai Nada, Kobe 657-8501, Japan

\subsection{Introduction}

The Mariana Trough is an active back-arc basin in the Philippine Sea plate (Fig. 18.1a). It has opened in the past 6 million years (Fryer 1996) and displays several different features of spreading mechanisms along its strike (e.g., Martinez et al. 2000; Kitada et al. 2006). The northern end of the Mariana Trough (north of $20^{\circ} 35^{\prime} \mathrm{N}$ ) displays a slow-spreading morphology (Martinez et al. 1995), although gravity data indicate the presence of thick crust that may 


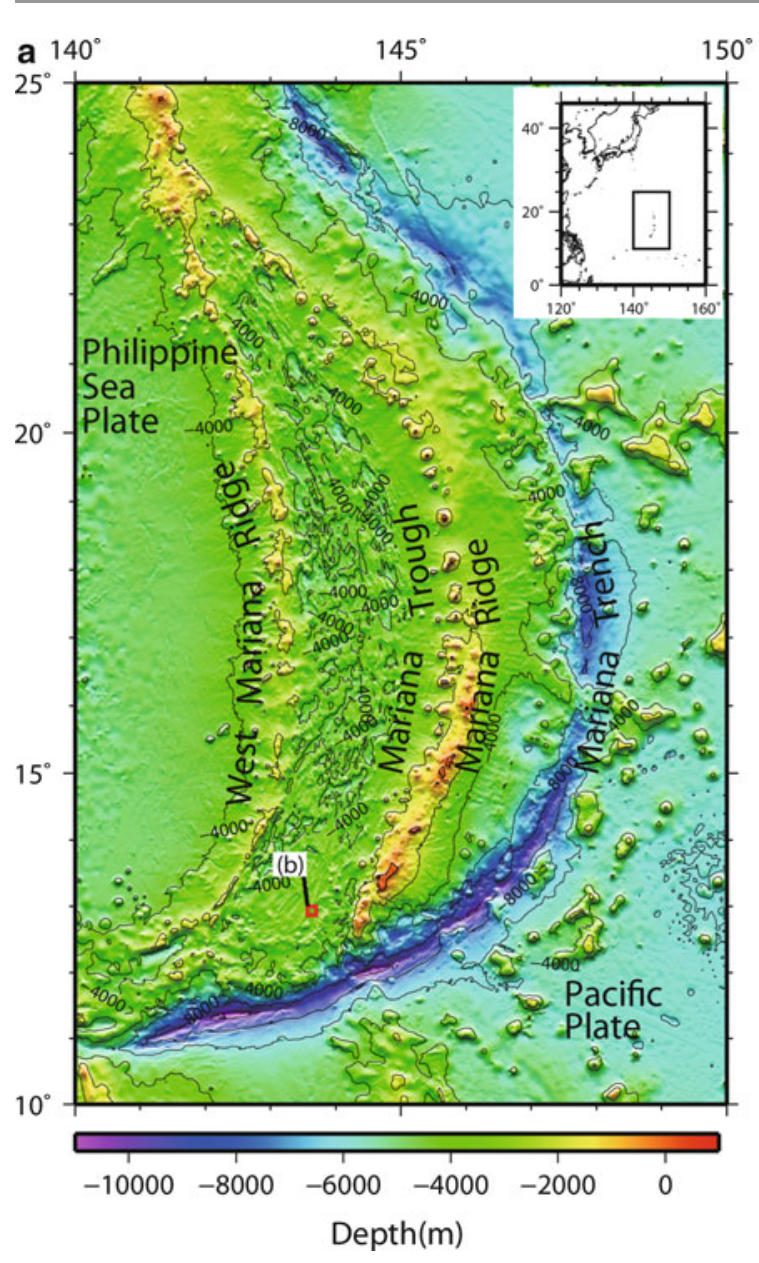

Fig. 18.1 (a) Bathymetric map of the Mariana Trough. The red square is the location of Fig. 18.1b. Contour interval is $2,000 \mathrm{~m}$. The bathymetry data are from Smith and Sandwell (1997). (b) Bathymetric map of hydrothermal sites at the southern end of the Mariana Trough. The red

reflect an additional magma supply from island arc sources (Yamazaki et al. 2003; Kitada et al. 2006). The northern central part (between $15^{\circ} 38^{\prime} \mathrm{N}$ and $20^{\circ} 35^{\prime} \mathrm{N}$ ) includes a segment of slow spreading with plume-like mantle upwelling under the axis and a segment of magma-starved slow spreading (Kitada et al. 2006). The southern central part (between $14^{\circ} 22^{\prime} \mathrm{N}$ and $15^{\circ} 38^{\prime} \mathrm{N}$ ) has thin crust that suggests a very low magma supply (Kitada et al. 2006). In the southern end of the Mariana Trough (south of $14^{\circ} 22^{\prime} \mathrm{N}$ ), although the full spreading rate of $46 \mathrm{~km} / \mathrm{Myr}$ is categorized as slow spreading (Seama and Okino, Chap. 28), an abundant magma supply is implied by high topographic relief at the spreading axis (Martinez et al. 2000), thick crust (Kitada et al. 2006), and a magma chamber reflector at $13^{\circ} 05^{\prime} \mathrm{N}$ (Becker et al. 2010).

In the southern end of the Mariana Trough, five hydrothermal sites have been documented (e.g., YK03-09, YK0509, and YK10-10 cruise reports) (Fig. 18.1b). The Snail and Yamanaka sites are on the spreading axis, the Archaean site stars indicate hydrothermal sites. The broken lines indicate ridge axes (Seama and Okino, Chap. 28). Contour interval is $50 \mathrm{~m}$. The bathymetric data are from Seama and Okino (Chap. 28)

is on the eastern foot of the axial high, and the Pika and Urashima sites are on an off-axis knoll about $5 \mathrm{~km}$ from the axis. The Snail site is an active hydrothermal system at a mound on pillow lavas cut by fissures (Urabe et al. 2004; Yoshikawa et al. 2012). Reported fluid temperatures are between $248{ }^{\circ} \mathrm{C}$ (Wheat et al. 2003) and $116{ }^{\circ} \mathrm{C}($ YK05-09 cruise report). The Yamanaka site is an inactive hydrothermal system with a white smoker and several inactive sulfide chimneys (YK03-09 cruise report). The Archaean site is an active system at a sulfide mound 50-100 m high (Urabe et al. 2004; Yoshikawa et al. 2012). Reported fluid temperatures there are $213{ }^{\circ} \mathrm{C}$ (Ishibashi et al. 2004) and $345^{\circ} \mathrm{C}$ (YK05-09 cruise report). The Pika site is an active system at the top of an off-axis knoll about $400 \mathrm{~m}$ high. The temperature of a black smoker there is $330{ }^{\circ} \mathrm{C}$ (Urabe et al. 2004). The Urashima site is at the northern foot of the off-axis knoll, and the reported temperature of a black smoker there is $280{ }^{\circ} \mathrm{C}$ (Nakamura et al. 2013). These hydrothermal systems are affected by on- and off-axis magma upwelling systems. 
Therefore, they are categorized as "TAIGA of sulfur" in the TAIGA Project (Urabe, Chap. 1), meaning that magma drives the hydrothermal system and degases sulfur species $\left(\mathrm{H}_{2} \mathrm{~S}, \mathrm{HS}^{-}\right)$that is utilized by microbes.

In studying hydrothermal features, it is important to investigate seismic structures and seismicity. For example, deMartin et al. (2007) used seismic refraction and microseismicity surveys at the TAG segment of the Mid-Atlantic Ridge to document a relationship between a hydrothermal system and an active detachment fault. Tolstoy et al. (2008) delineated along-axis hydrothermal circulation pathways using microearthquake observations on the East Pacific Rise. Using these methods to image melt delivery to spreading axes and off-axis areas, and to trace pathways and heat sources for hydrothermal circulation, can provide important constraints for modeling relations between a spreading system and its related hydrothermal system.

The present study investigated relations between the back-arc spreading system and the hydrothermal system in the Southern Mariana Trough using a seismic reflection/ refraction survey and seismicity observations.

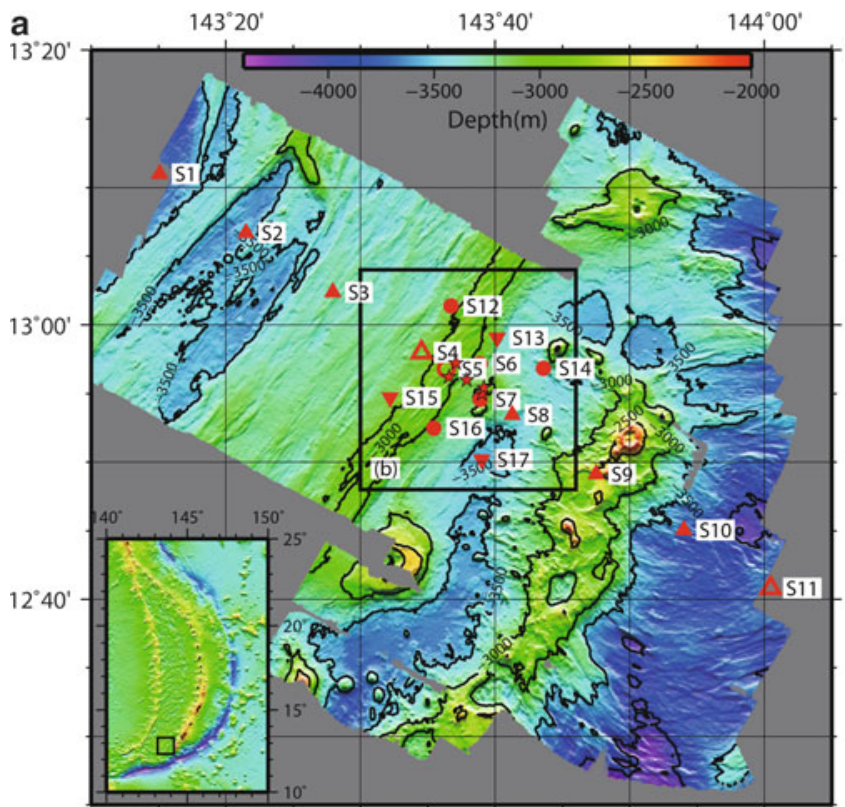

Fig. 18.2 (a) Map of OBS locations. The red triangles indicate LTOBS_ERI, the red circles indicate STOBS_ERI, and the red inverted triangles represent STOBS_Chiba instruments. Filled and open symbols indicate OBSs with data and no data, respectively. The red stars indicate hydrothermal sites. Contour interval is $500 \mathrm{~m}$. The bathymetric data are from Seama and Okino (Chap. 28). (b) Profile map

\subsection{Data Acquisition and Analysis Methods}

We conducted a seismic reflection/refraction survey and seismicity observation at the hydrothermal area in the southern end of the Mariana Trough (Fig. 18.2) from August to November 2010 using S/V Yokosuka of the Japan Agency for Marine-Science and Technology (JAMSTEC) (YK10-10 and YK10-15 cruise reports). We used 17 ocean bottom seismometers (OBSs), an airgun, and a single-channel streamer cable.

The digital OBSs used were of three types. The LTOBS_ERI instrument (used at sites S1-S4 and S8-S11) was deployed in a $50 \mathrm{~cm}$ titanium sphere and equipped with a three-component velocity seismometer of $1 \mathrm{~Hz}$ natural frequency and a 24-bit analog-to-digital (A/D) converter. The data sampling rate was $200 \mathrm{~Hz}$. The STOBS_ERI instrument (used at sites S5-S7, S12, S14, and S16) was deployed in a $40 \mathrm{~cm}$ glass sphere and equipped with a three-component $4.5 \mathrm{~Hz}$ velocity seismometer and a 24-bit A/D converter. The data sampling

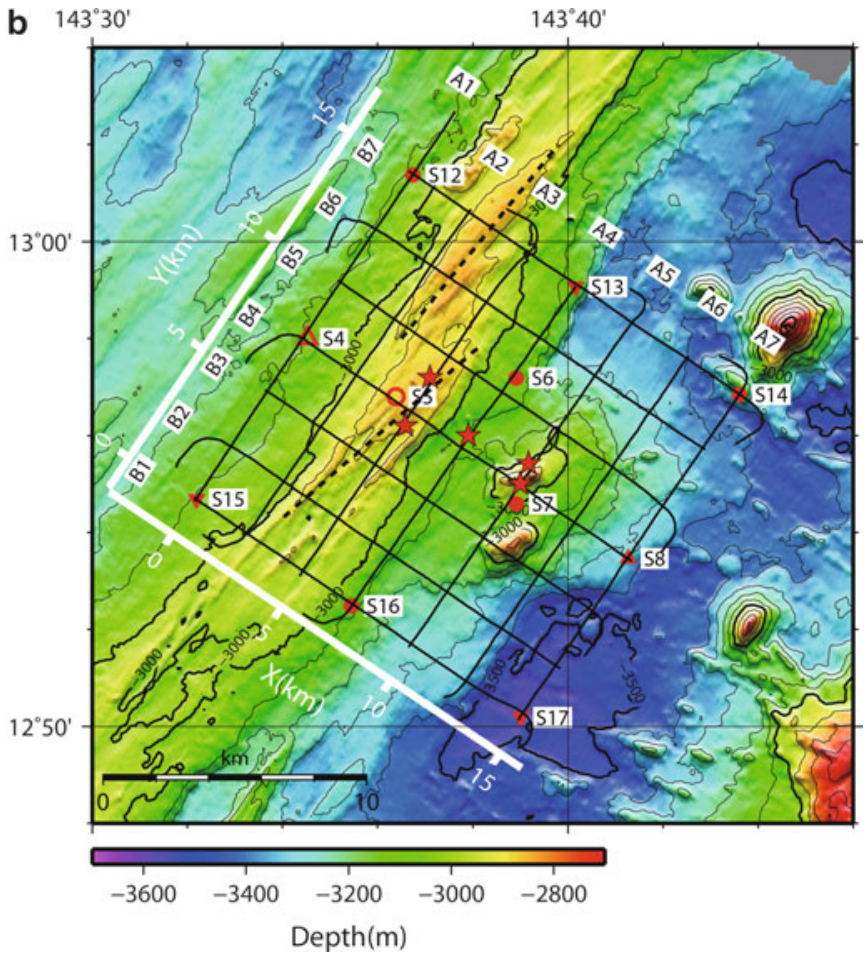

of the seismic reflection/refraction survey. The black lines indicate airgun survey profiles. Survey lines A1-A7 and B1-B7 are shown. The red triangles, circles, and inverted triangles indicate OBSs. The red stars indicate hydrothermal sites. The broken lines indicate ridge axes. Contour interval is $100 \mathrm{~m}$. Axes in white indicate the coordinate system used in the $3 \mathrm{D}$ inversion 
rate was $200 \mathrm{~Hz}$. The STOBS_Chiba instrument (S13, S15, and S17) used a $40 \mathrm{~cm}$ glass sphere equipped with a threecomponent $4.5 \mathrm{~Hz}$ velocity seismometer and a 24-bit A/D converter. The data sampling rate was $125 \mathrm{~Hz}$. All OBSs used a crystal oscillator with a precision greater than $5 \times 10^{-7} \mathrm{~s}$. We determined the location of each OBS at the seafloor through acoustic ranging and ship GPS positions. The accuracy of the OBS positions is estimated to be a few to a few tens of meters. We obtained seismic data from 14 of the 17 OBSs (S1-S3, S6-S10, and S12-S17).

We conducted a seismic reflection/refraction survey of the hydrothermal area to compile a 3D seismic structure image (Fig. 18.2b). Seven lines (A1-A7) ran NE-SW parallel to the spreading axis, and seven lines (B1-B7) ran NW-SE perpendicular to the spreading axis. Lines were $15 \mathrm{~km}$ long and the interval between lines was $2.5 \mathrm{~km}$. The airgun was a GI gun with a volume of $355 \mathrm{cu}$. in. $(5.5 \mathrm{~L})$ and air pressure of $13.5 \mathrm{MPa}$. The shot interval was $40 \mathrm{~s}$, for a shot spacing of about $97 \mathrm{~m}$. We fired 2,519 shots along the profiles. Data from nine OBSs (S6-S8, S12-S17) were used for the seismic refraction analysis. Figure 18.3 shows an example of waveform data obtained by OBSs S12 and S6 from airgun shots. Seismic reflection data were obtained using a single-channel streamer combining 48 hydrophone signals, and the data were recorded with a duration of $16 \mathrm{~s}$ and sampling rate of $1,000 \mathrm{~Hz}$ for each shot.

To obtain the seismic velocity structure under the hydrothermal area, we carried out $2 \mathrm{D}$ traveltime inversions for lines A1, A4, A7, B1, B4, and B7 using first arrivals. We used the progressive model development method (Sato and Kennett 2000) to estimate 2D cross-sections of the seismic velocity structure under each line. Then we constructed a 3D initial seismic velocity model by interpolating among the 2D structures. This initial model also included bathymetric data (Seama and Okino, Chap. 28). Using this initial model, we carried out a tomographic inversion using first arrivals (Zelt and Barton 1998). We also conducted checkerboard tests to assess the reliability of estimated structures.

For analyzing seismicity, we used the WIN processing system for waveform data from microearthquake networks (Urabe and Tsukada 1991). To detect seismic events, we used an event picker algorithm based on the ratio between the short-term average and long-term average of amplitude of recorded wave-form, and duration of events. We extracted events that were recorded at two or more stations. $\mathrm{P}$ - and $\mathrm{S}$-wave arrival times were hand-picked. Hypocenters were determined by the HYPOMH algorithm, which uses a maximum-likelihood estimation technique with origin time eliminated (Hirata and Matsu'ura 1987).

\subsection{Results}

\subsubsection{Seismic velocity structure}

For the 3D refraction analysis, we used 9028 hand-picked $\mathrm{P}$-wave arrivals. We set the error in P-wave arrivals at $30 \mathrm{~ms}$, as estimated from errors in arrival-time picks $(20-30 \mathrm{~ms})$, shot/receiver position (less than $10 \mathrm{~ms}$ ), and OBS clock drift (less than $5 \mathrm{~ms}$ ). The initial model for the 3D tomographic inversion (Fig. 18.4a-e) had RMS traveltime residuals between predicted and observed arrivals of $109 \mathrm{~ms}$ and showed roughly parallel structures along the spreading ridge axis. In the $3 \mathrm{D}$ inversion, we iterated toward a model with a chi-square value $\chi^{2}$ (normalized RMS of traveltime residuals) of one, which means that the RMS traveltime residual was $30 \mathrm{~ms}$ for estimated models. An example of the picked arrivals and synthetic arrivals of the initial and final models is shown in Fig. 18.3.

Figures $18.4 \mathrm{f}-\mathrm{j}$ and 18.5 show the final model estimated using the 3D tomographic inversion, and Figs. 18.6 and 18.7 show a checkerboard test and ray paths for the final model. For the checkerboard test, we adopted a velocity perturbation of $5 \%$ from the final model and a perturbation grid size of $3 \times 3 \mathrm{~km}$ horizontal and $1 \mathrm{~km}$ vertical for shallower than $5.5 \mathrm{~km}$ from the sea surface, and $5 \times 5 \mathrm{~km}$ horizontal and $1 \mathrm{~km}$ vertical for deeper than $5.5 \mathrm{~km}$. We made a set of pseudo-data consisting of synthetic $\mathrm{P}$-wave arrivals with the same source-receiver pairs as the picked data using the test model and random errors with standard deviation of $30 \mathrm{~ms}$. The results of the checkerboard test showed that the pattern of the velocity variation was recovered well at depths shallower than $6.5 \mathrm{~km}$ from the sea surface, and ray path coverage shallower than $6.5 \mathrm{~km}$ was good over the survey area. Therefore, we confirm that our inversion results can distinguish the three hydrothermal areas (Snail + Yamanaka, Archaean, and Pika + Urashima).

The final model displays four main features of the crustal structure around the back-arc spreading ridge with hydrothermal activity. (1) The average thickness of layer 2 of the oceanic crust in the survey area is about $3 \mathrm{~km}$ if we put the boundary between layer 2 and layer 3 at $V_{P} 6 \mathrm{~km} /$ $\mathrm{s}$ and assume no sedimentary layer around the ridge (Fig. $18.4 \mathrm{k}$ ). In general, seismic velocity of layer 2 is about $\mathrm{V}_{\mathrm{P}} 3-6 \mathrm{~km} / \mathrm{s}$ with large velocity gradient, and that of layer 3 is about $V_{P} 6-7 \mathrm{~km} / \mathrm{s}$ with less velocity gradient (e.g., Kearey et al. 2009). Our results show a velocity gradient change at the depth of $6.5 \mathrm{~km}$ with $\mathrm{V}_{\mathrm{P}} 6 \mathrm{~km} / \mathrm{s}$. Thus, we set the boundary between layer 2 and layer 3 at $V_{P}$ $6 \mathrm{~km} / \mathrm{s}$. The $3 \mathrm{~km}$ thickness of layer 2 means that this area has a thicker layer 2 than in normal oceanic crust, where it is about $1-2 \mathrm{~km}$ thick (e.g., Kearey et al. 2009). Moreover, the survey area has a low-velocity layer $2(\sim 4.0 \mathrm{~km} / \mathrm{s}$ at 

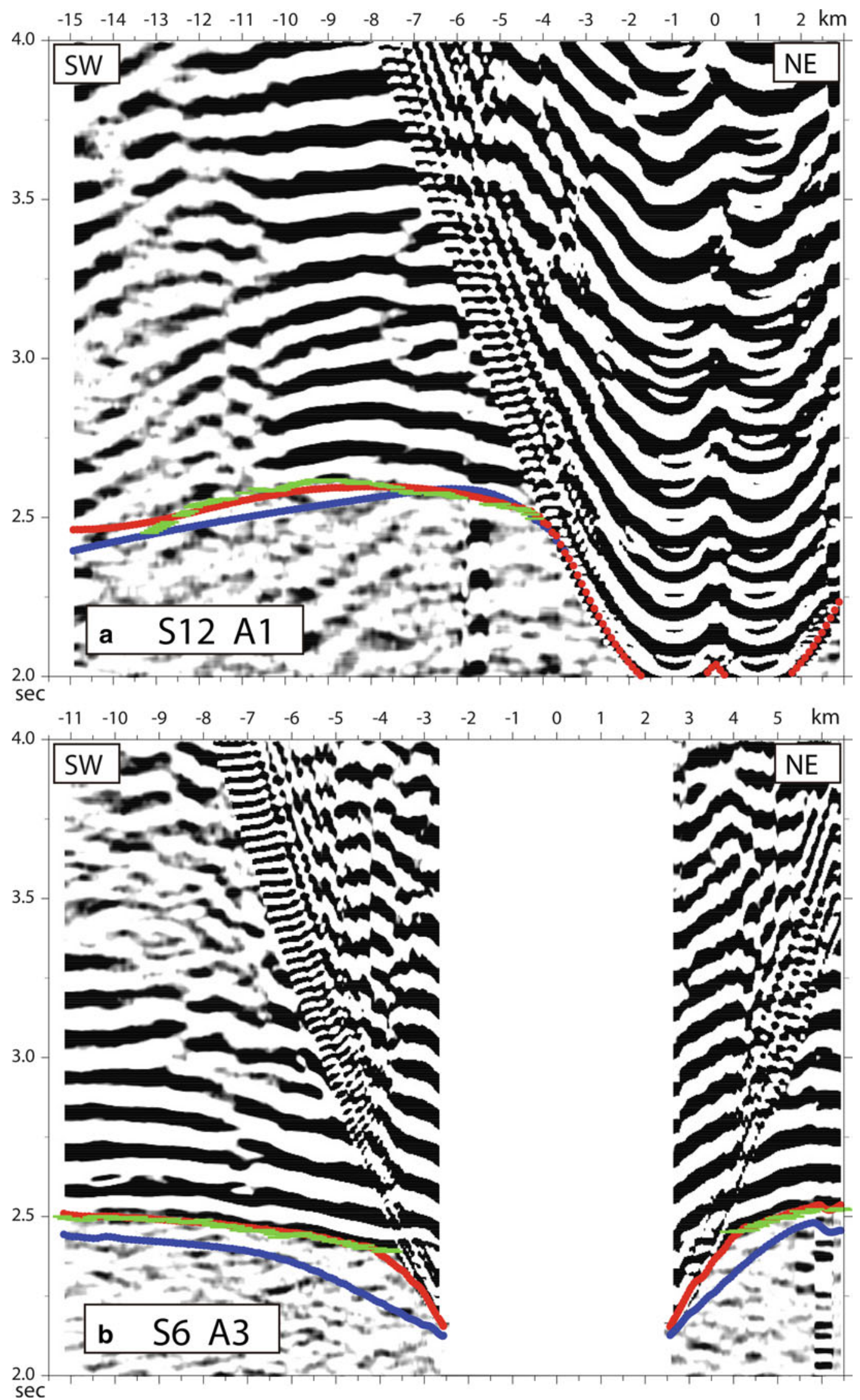

Fig. 18.3 Examples of seismograms. (a) Line A1 recorded by OBS S12; (b) line A3 recorded by OBS S6. Horizontal axis indicates distance from OBS to shots. Vertical axis is traveltime. Reduction velocity is $5 \mathrm{~km} / \mathrm{s}$. Green lines indicate observed (picked) traveltimes. Blue lines indicate synthetic traveltimes for the initial model. Red lines indicate synthetic traveltimes for the final model 

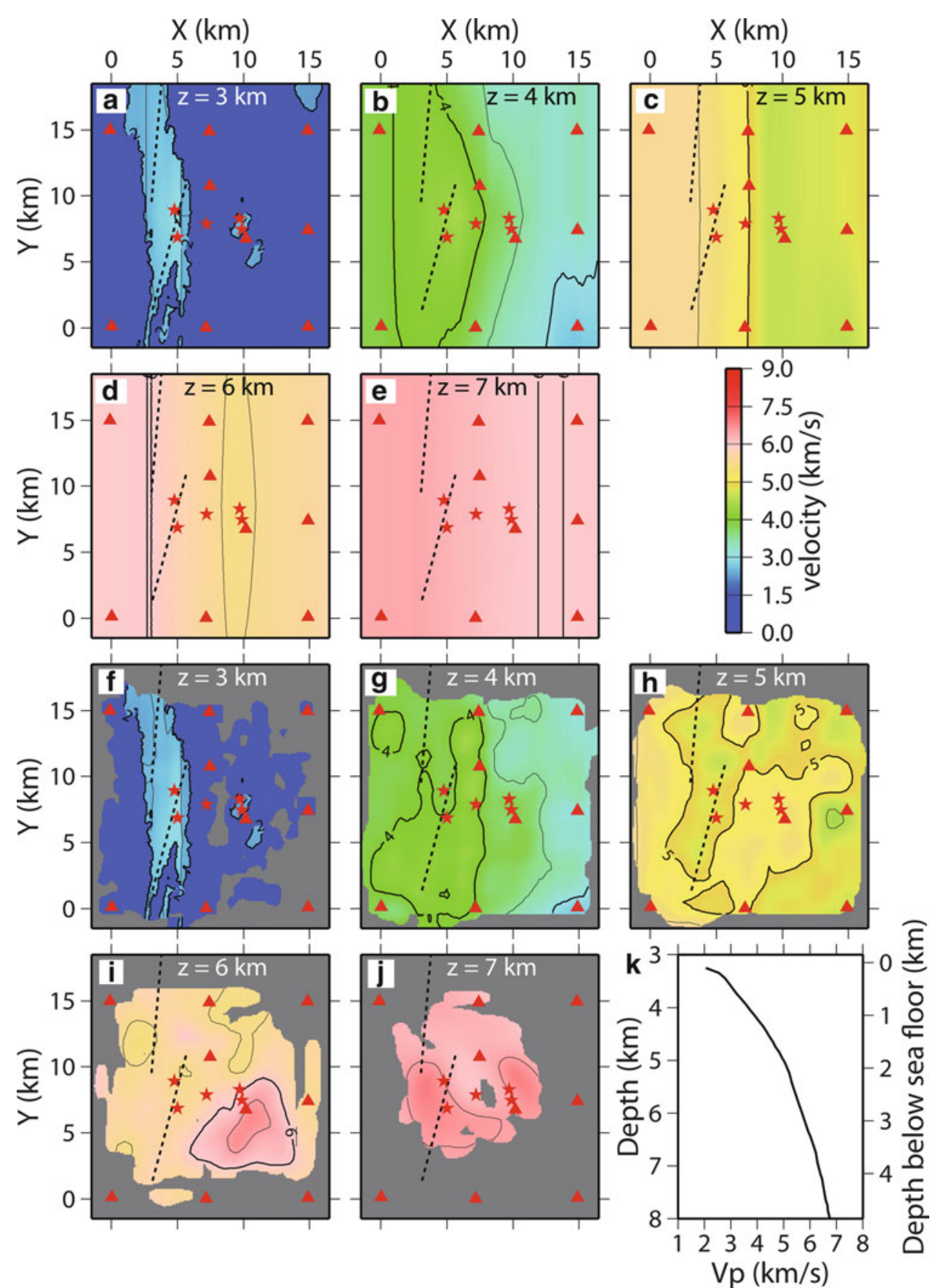

Fig. 18.4 (a-e) Map views of velocity structure of the initial model. Depth ( $\mathrm{z}$ ) is from the sea surface. Contour interval is $0.5 \mathrm{~km} / \mathrm{s}$. The red triangles indicate OBSs. The red stars indicate hydrothermal sites. The broken lines indicate ridge axes. (f-j) Map views of velocity

structure of the final model. Gray areas indicate no ray paths. (k) 1D average velocity of the final model. Average velocities are taken at each depth below the seafloor

$1 \mathrm{~km}$ depth below sea floor). (2) The velocity just beneath the spreading ridge is lower than in the surrounding area (see map views at depths of 4 and $5 \mathrm{~km}$ in Fig. 18.4g, h and $\mathrm{V}_{\mathrm{P}}$ anomalies in Fig. 18.5g-i relative to the 1D average in Fig. 18.4k). This low-velocity zone lies beneath the area including the Snail and Yamanaka hydrothermal sites. (3) There is a high-velocity area just beneath the off-axis knoll

(see map view at $6 \mathrm{~km}$ depth in Fig. 18.4i). This knoll is the location of the Pika and Urashima hydrothermal sites. Cross-sections through the two hydrothermal sites (Fig. 18.5c, e) show that the boundary between layers 2 and 3 is convex upward beneath the knoll. (4) At the Archaean hydrothermal site, there are no anomalous structures. 


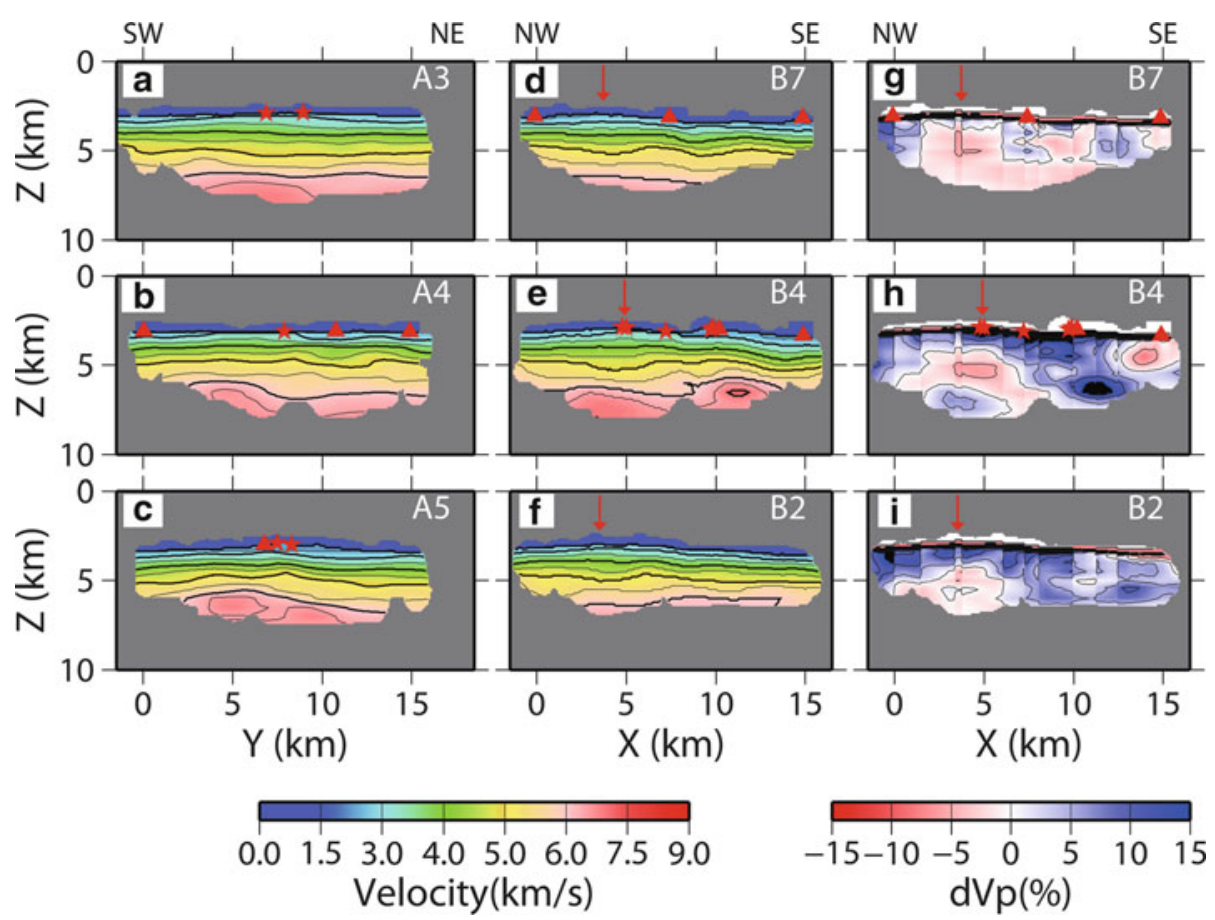

Fig. 18.5 (a-c) Vertical cross sections of $V_{P}$ distribution beneath ridge-parallel lines A3, A4, and A5. Contour interval is $0.5 \mathrm{~km} / \mathrm{s}$. Gray areas indicate no ray paths. The red triangles indicate OBSs on the line. The red stars indicate hydrothermal sites on the line. $(\mathbf{d}-\mathbf{f})$ Vertical cross sections of $V_{P}$ distribution beneath ridge-perpendicular

From the seismic reflection data, we cannot identify reflectors consistent with axial magma chambers. Some data show reflective images at the Pika and Urashima hydrothermal sites, but we cannot distinguish these from scattered returns from the rough surfaces of the off-axis knoll. A multichannel seismic survey would be needed to reveal detailed structures here.

\subsubsection{Seismicity}

We obtained 3 months of seismicity data at the southern end of the Mariana Trough from 14 of the 17 deployed OBSs. We used a 1D P-wave velocity model (Fig. 18.8) based on the results of this study, the velocity structures of the middle Mariana Trough published by Takahashi et al. (2008), and the IASP91 velocity model (Kennett 1991). We assumed the $\mathrm{V}_{\mathrm{P}} / \mathrm{V}_{\mathrm{S}}$ ratio to be 1.73 .

During the observation period, we determined hypocenters of about 1,700 events (Fig. 18.9). Most events occurred at and around areas of high topographic relief, which are probably arc volcanoes, about $30 \mathrm{~km}$ southeast of the spreading ridge. The hydrothermal areas had very few events during the observation period. We determined only two hypocenters within $5 \mathrm{~km}$ of the hydrothermal areas. lines B7, B4, and B2. The red arrow indicates the ridge axis. (g-i) Vertical cross sections of $V_{P}$ anomalies relative to the $1 D$ average velocity of the final model (Fig. $18.4 \mathrm{k}$ ) beneath ridge-perpendicular lines B7, B4, and B2

Some OBSs recorded small tremors like noise. We could not identify these as volcanic tremors, because these tremors were too small to obtain sufficient arrival time data, then we could not determine locations of these tremors. To identify these tremors whether as volcanic or not, we would need more dense OBS arrays.

\subsection{Discussion}

Our observations revealed a detailed seismic velocity structure and a record of seismicity at and around the hydrothermal areas in the Southern Mariana Trough. We can evaluate the heat sources of the hydrothermal activity from these results.

The spreading axis, where the Snail and Yamanaka hydrothermal sites are located, has lower seismic velocities than the surrounding area. This suggests that the area beneath the axis is hotter due to magmatic activity and thus that the heat source of these sites may be magmatic. Kitada et al. (2006) suggested on the basis of gravity data that there are sheetlike mantle upwellings beneath the first-order ridge segments in the southern end of the Mariana Trough. Our results show more detailed structures. The map view at $5 \mathrm{~km}$ depth (Fig. 18.4h) displays that the low-velocity structure 
Fig. 18.6 Checkerboard test. (a-e) Given model. We adopted a velocity perturbation of $5 \%$ from the final model and a perturbation grid size of $3 \times 3 \mathrm{~km}$ horizontal and $1 \mathrm{~km}$ vertical for shallower than $5.5 \mathrm{~km}$ from the sea surface, and $5 \times 5 \mathrm{~km}$ horizontal and $1 \mathrm{~km}$ vertical for deeper than $5.5 \mathrm{~km}$. The triangles indicate used OBSs. The stars indicate hydrothermal sites. (f-j) Recovered model after the inversion

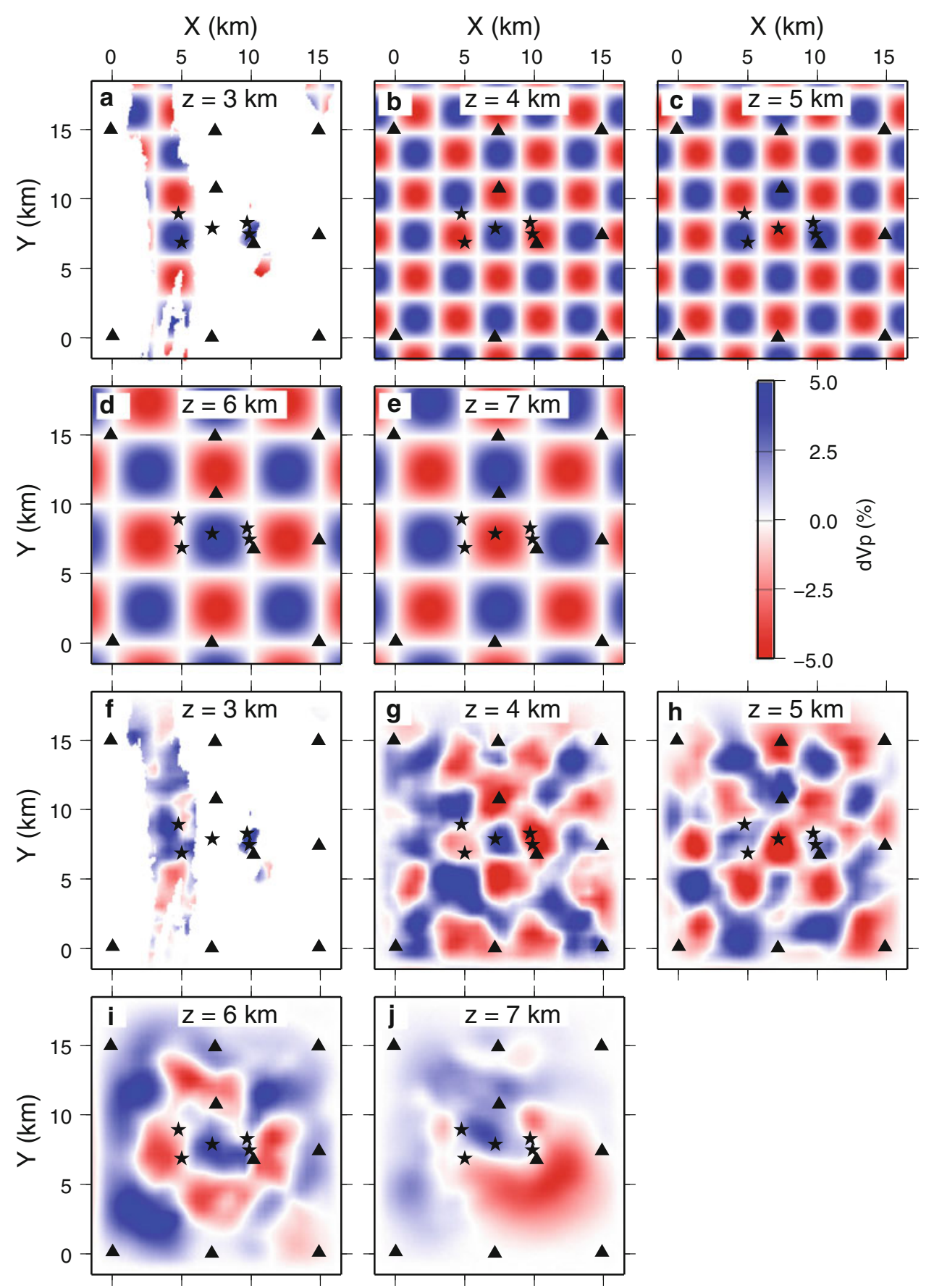

aligns with the subdivided axes. Our results suggest that the upwellings beneath the first-order ridge segment can be subdivided into upwellings beneath the third-order ridge segment which is pointed by Seama et al. (Chap. 17). The depth of the top of the low-velocity zones is about $4.5 \mathrm{~km}$, or $1.5 \mathrm{~km}$ below the seafloor (Fig. $18.5 \mathrm{~g}-\mathrm{i}$ ). As the seismic reflection profile of Becker et al. (2010) shows no magma chamber reflector in our study area, the low-velocity zone is probably not a magma chamber with abundant melt, but a warm zone with a chamber of crystal-rich mush.
At the off-axis knoll, where the Pika and Urashima hydrothermal sites are located, we mapped a high-velocity structure with convex upward that suggests a volcanic activity beneath the knoll. We infer that off-axis volcanism once existed there, forming the knoll, and intruded magma was cooled to become layer 3, making the boundary between layers 2 and 3 convex upward. Previous results also support this conclusion. Yoshikawa et al. (2012) interpreted nearbottom swath mapping data showing an undeformed morphology of the knoll to suggest that the knoll is related to an 
Fig. 18.7 (a-e) Ray paths of the final model. Each panel shows ray paths within $0.5 \mathrm{~km}$ of $\mathrm{z}$. The red triangles indicate OBSs. The red stars indicate hydrothermal sites

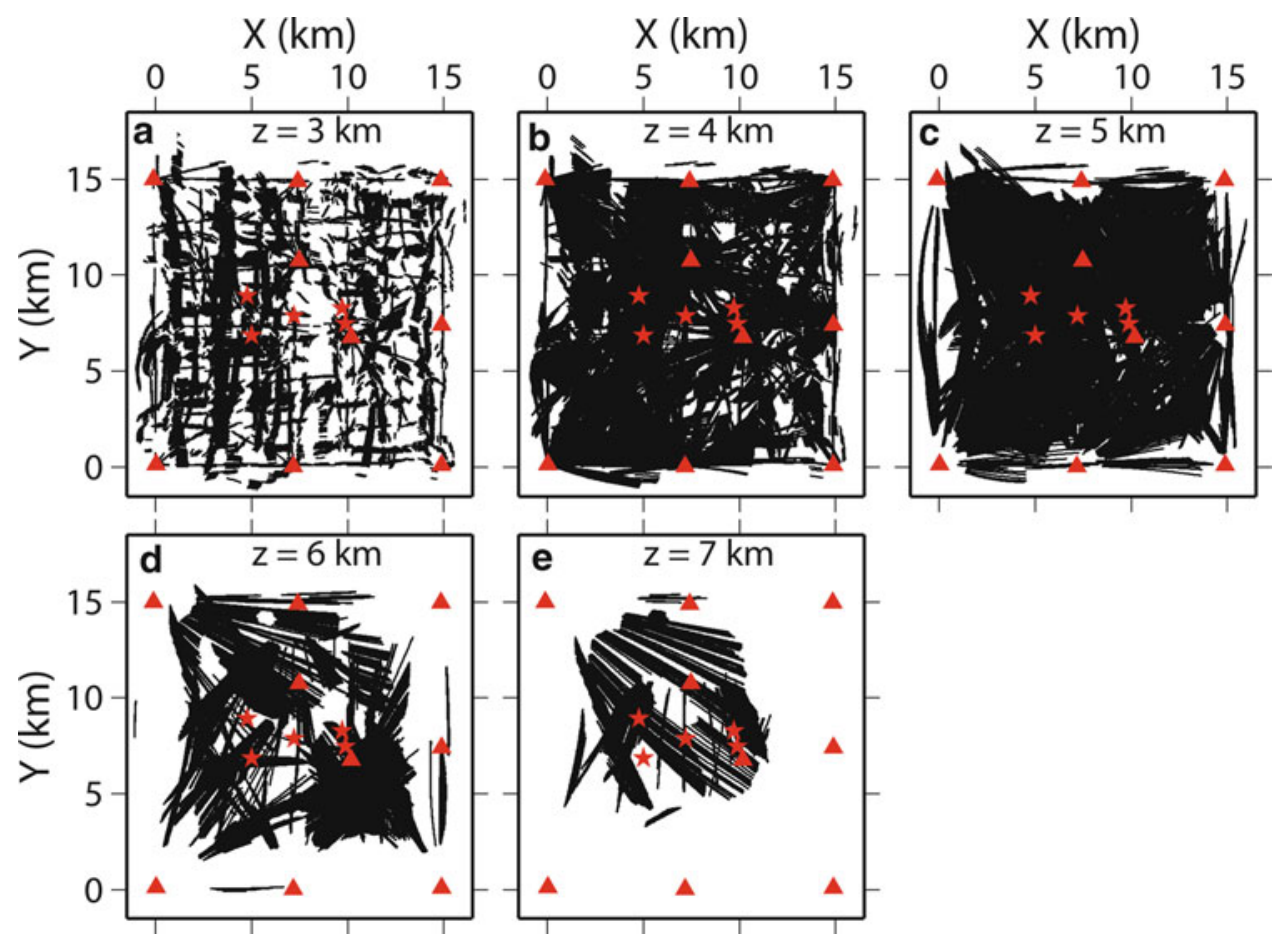

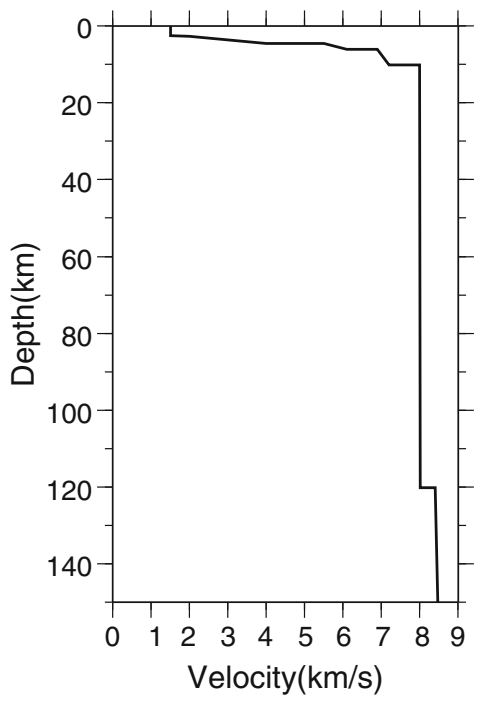

Fig. 18.8 1D velocity structure used for hypocenter determination

off-axis magma upwelling system. Kakegawa et al. (2008) showed that the knoll is composed of pillow lavas with minor sediment cover, indicating that volcanic activity have ceased. The very low seismic activity at the knoll also suggests the cessation. Hence the heat sources of the Pika and Urashima sites may be residual heat from this off-axis magmatic activity.

At the Archaean hydrothermal site, we did not find any anomalous structures like those at the other hydrothermal sites. This site consists of a small mound $250-300 \mathrm{~m}$ in diameter and $50-100 \mathrm{~m}$ high in a flat basin at the eastern foot of the axial high (Yoshikawa et al. 2012), too small for our seismic survey to reveal any internal structure. A higherresolution survey is required to obtain a detailed structure at this site.

Our seismic observations found very low seismicity at the hydrothermal sites. This result is very different from those of deMartin et al. (2007) and Tolstoy et al. (2008), who found many microearthquakes related to hydrothermal activity. The difference may be because our OBS network had a wider spacing (about $5 \mathrm{~km}$ ) than the earlier networks (about $1-5 \mathrm{~km}$ ). To examine this possibility, we checked the seismicity near OBS S7, which was less than $1 \mathrm{~km}$ from the Pika hydrothermal site. Looking at the S-P times of all events recorded by OBS S7 (Fig. 18.10), we found that it recorded only three events with S-P times less than $1 \mathrm{~s}$. This indicates that the very low seismicity was not an artifact of our OBS network, but a real feature in the study area, and it suggests that there are no faults or fractures related to the hydrothermal activity. That in turn suggests that hydrothermal activity here is not related to tectonic stresses. Yoshikawa et al. (2012) likewise reported no fault systems at the off-axis hydrothermal sites Archaean, Pika, and Urashima.

We found a thick layer 2 (thickness about $3 \mathrm{~km}$ ) with low seismic velocities over the study area. Figure 18.11 shows the $1 \mathrm{D}$ velocity profile of this study along with those for the Central Mariana Trough (Takahashi et al. 2008), the Lau basin (Jacobs et al. 2007; Dunn and Martinez 2011), the Juan de Fuca Ridge (Christensen et al. 1993), the East Pacific Rise (Vera et al. 1990), and the Mid-Atlantic Ridge (Magde et al. 

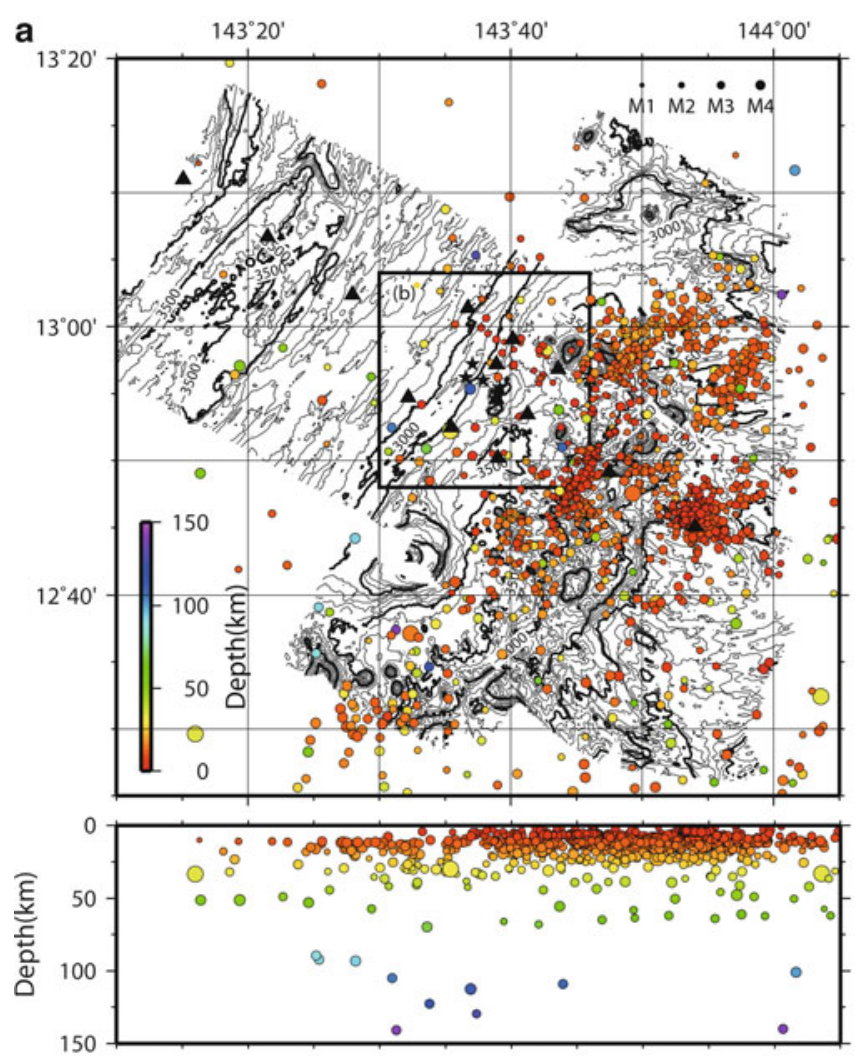

Fig. 18.9 (a) Hypocenter distribution at the Southern Mariana Trough during three months of observations by OBSs (triangles). The stars indicate the hydrothermal sites. Contour interval is $100 \mathrm{~m}$. (b) Hypocenter distribution near the hydrothermal sites. Only high-quality

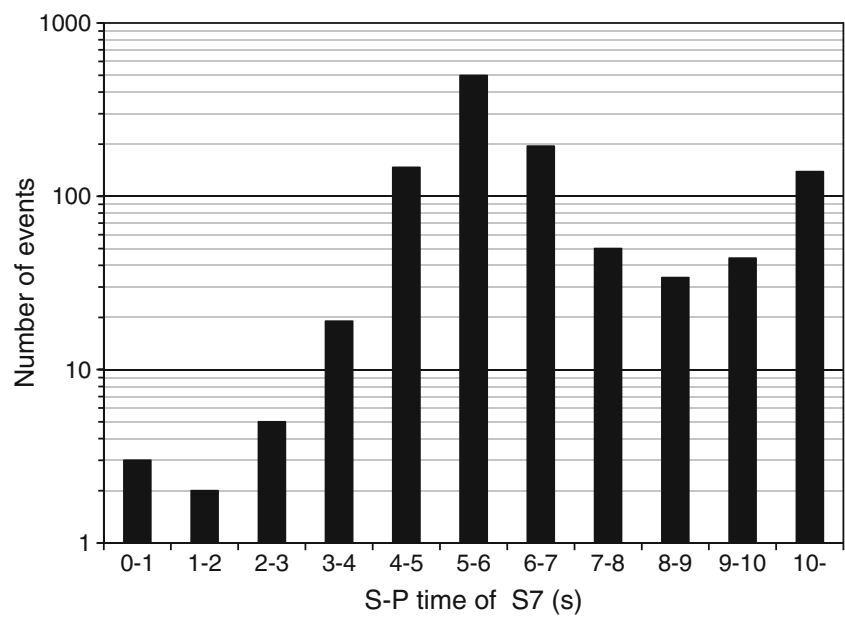

Fig. 18.10 Histogram of S-P times at OBS S7

2000). It shows that the Southern Mariana Trough has a thicker layer 2 and lower seismic velocities than the normal mid-ocean ridges (Juan de Fuca Ridge, East Pacific Rise, and Mid-Atlantic Ridge). In the back-arc spreading ridges, the structures are divided into two groups. One, which includes the Central Mariana Trough and the Lau Domain III, is

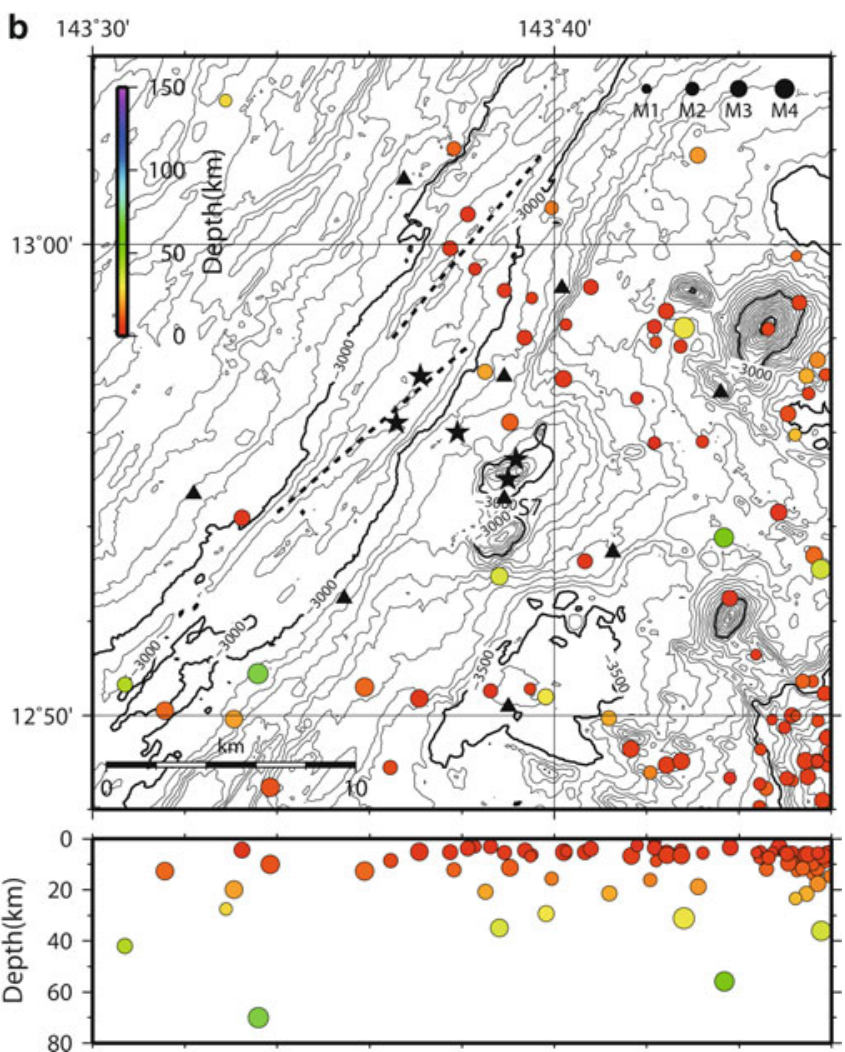

hypocenters whose standard error in each of the hypocenter coordinates is less than $5 \mathrm{~km}$ are plotted. The broken lines indicate ridge axes. Contour interval is $50 \mathrm{~m}$

similar to mid-ocean ridges, and the other, which includes the Southern Mariana Trough, Lau Domain II, and Lau Valu Fa Ridge, has a low-velocity layer 2. Jacobs et al. (2007) and Dunn and Martinez (2011) noted that the low-velocity layer 2 implies high porosities and arc-related mineralogies, and that the Domain II and Valu Fa Ridge in the Lau basin are formed by magmas with high volatile contents derived from the subducting plate, because these areas are near the subduction slab and the Tonga volcanic arc. As the Southern Mariana Trough also is near the subduction zone and the volcanic arc, and as its seismic structure is similar to Lau Domain II and Valu Fa Ridge, we suggest that the upwelling mantle beneath the Southern Mariana Trough spreading axis is influenced by subduction. The upwelling mantle would have low viscosity due to hydration by water from the subducting slab, and the magmas produced would form thicker crust with high porosities ( $=$ lower velocities) in the Southern Mariana Trough. The Central Mariana Trough, on the other hand, is far from the subduction zone, hence its crustal structure would be similar to mid-ocean ridges, and there may be no influence of subduction as suggested by the upper mantle electrical resistivity structure reported by Matsuno et al. (2010). 


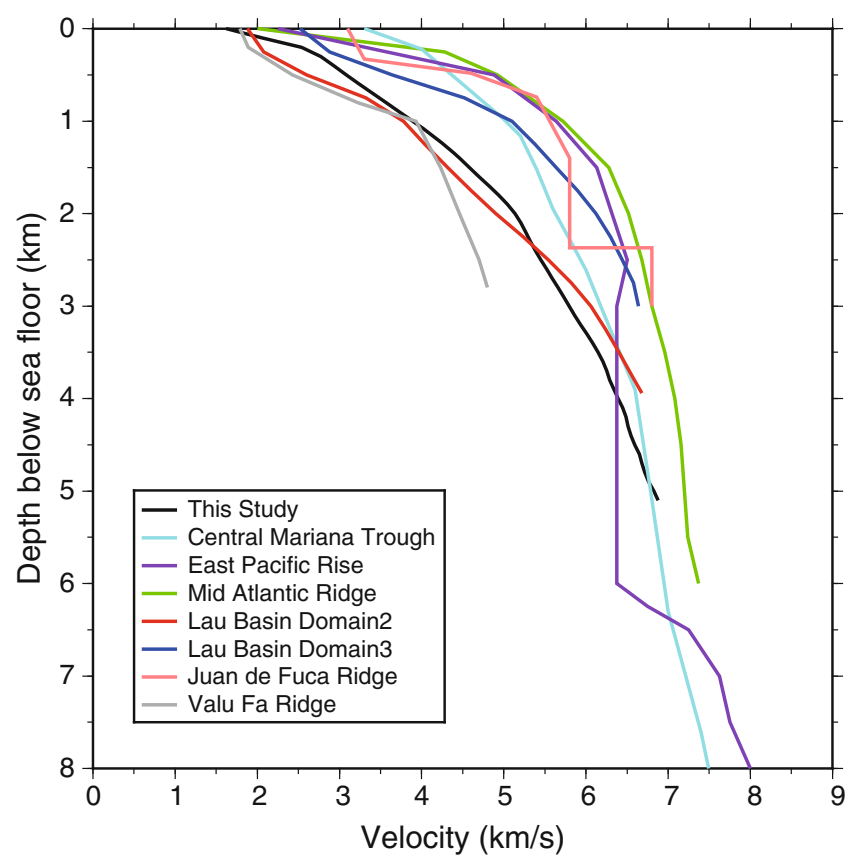

Fig. 18.11 Comparison of 1D velocity structures at spreading ridges of the Southern Mariana Trough (this study), the Central Mariana Trough (Takahashi et al. 2008), East Pacific Rise (Vera et al. 1990), Mid-Atlantic Ridge (Magde et al. 2000), Lau Basin (Dunn and Martinez 2011), Juan de Fuca Ridge (Christensen et al. 1993), and Valu Fa Ridge (Jacobs et al. 2007)

Our seismicity study recorded many microearthquakes beneath the area of high topographic relief that probably represents arc volcanoes. This means that this area is now very active. Fryer et al. (1998) suggested that the morphology of these volcanoes indicates recent activity. More detailed seismicity surveys may reveal this volcanic activity.

\subsection{Conclusions}

We conducted a seismic reflection/refraction survey and a seismicity observation campaign at the hydrothermal area in the southern end of the Mariana Trough. From a 3D refraction analysis, we found that the spreading axis has a lowvelocity structure suggesting the presence of magmatic activity beneath the axis. The low-velocity structure shows sheetlike mantle upwellings beneath the third-order ridge segments that may be the heat sources for the Snail and Yamanaka hydrothermal sites. Beneath an off-axis knoll, we found a high-velocity structure with convex upward that is consistent with off-axis volcanism in the area. The very low seismicity there suggests that this volcanism may have ceased. The heat sources of the Pika and Urashima hydrothermal sites may be residual heat from this off-axis volcanic activity. We detected a thick (about $3 \mathrm{~km}$ ) layer 2 with low seismic velocities over the survey area. A comparison of this structure with other back-arc spreading centers and mid-ocean ridges suggests that the crust was formed by magmas with high volatile contents, probably due to upwelling mantle influenced by subduction. Our seismic observations documented very low seismicity at the hydrothermal sites, indicating that there are no faults or fractures related to the hydrothermal activity. This suggests that the hydrothermal activity is not related to tectonic stresses.

Acknowledgments We thank the captain and crew of S/V Yokosuka of JAMSTEC for their support. This paper has been improved by comments from reviewers. The figures were generated using GMT software (University of Hawaii; Wessel and Smith (Wessel and Smith 1998)). This work was supported by Grant-in-Aid for Scientific Research on Innovative Areas of the Ministry of Education, Culture, Sports, Science and Technology (Grant Number 20109002, TAIGA project).

Open Access This chapter is distributed under the terms of the Creative Commons Attribution Noncommercial License, which permits any noncommercial use, distribution, and reproduction in any medium, provided the original author(s) and source are credited.

\section{References}

Becker NC, Fryer P, Moore GF (2010) Malaguana-Gadao Ridge: identification and implications of a magma chamber reflector in the southern Mariana Trough. Geochem Geophys Geosyst 11: Q04X13. doi:10.1029/2009GC002719

Christensen GL, Purdy GM, Rohr KMM (1993) Structure of the northern symmetrical segment of the Juan de Fuca Ridge. Mar Geophys Res 15:219-240

deMartin BJ, Sohn RA, Canales JP, Humphris SE (2007) Kinematics and geometry of active detachment faulting beneath the TransAtlantic Geotraverse (TAG) hydrothermal field on the Mid-Atlantic Ridge. Geology 35:711-714

Dunn RA, Martinez F (2011) Contrasting crustal production and rapid mantle transitions beneath back-arc ridges. Nature 469:198-202

Fryer P (1996) Evolution of the Mariana convergent plate margin system. Rev Geophys 34:89-125

Fryer P, Fujimoto H, Sekine M, Johnson M, Kasahara J, Masuda H, Gamo T, Ishii T, Ariyoshi M, Fujioka K (1998) Volcanoes of the southwestern extension of the active Mariana Island Arc: new swath-mapping and geochemical studies. Isl Arc 7:596-607

Hirata N, Matsu'ura M (1987) Maximum-likelihood estimation of hypocenter with origin time eliminated using nonlinear inversion technique. Phys Earth Planet Inter 47:50-61

Ishibashi J, Yamanaka T, Kimura H, Hirota A, Toki T, Tsunogai U, Gamo T, Utsumi M, Roe K, Miyabe S, Okamura K (2004) Geochemistry of hydrothermal fluids in South Mariana Backarc Spreading Center. Eos Trans AGU 85(47), Fall Meet Suppl, Abstract V44A-05

Jacobs AM, Harding AJ, Kent GM (2007) Axial crustal structure of the Lau back-arc basin from velocity modeling of multichannel seismic data. Earth Planet Sci Lett 259:239-255

Kakegawa T, Utsumi M, Marumo K (2008) Geochemistry of sulfide chimneys and basement pillow lavas at the southern Mariana Trough $\left(12.55^{\circ} \mathrm{N}-12.58^{\circ} \mathrm{N}\right)$. Resource Geol 58:249-266

Kearey P, Klepeis KA, Vine FJ (2009) Global tectonics, 3rd edn. Wiley-Blackwell, West Sussex, UK 
Kennett BLN (1991) IASPEI 1991 seismological tables, Research School of Earth Sciences, Australian National University, 167 pp

Kitada K, Seama N, Yamazaki T, Nogi Y, Suyehiro K (2006) Distinct regional differences in crustal thickness along the axis of the Mariana Trough, inferred from gravity anomalies. Geochem Geophys Geosyst 7, Q04011. doi:10.1029/2005GC001119

Magde LS, Barclay AH, Toomey DR, Detrick RS, Collins JA (2000) Crustal magma plumbing within a segment of the Mid-Atlantic Ridge, $35^{\circ}$ N. Earth Planet Sci Lett 175:55-67

Martinez F, Fryer P, Baker NC, Yamazaki T (1995) Evolution of backarc rifting Mariana Trough $20-24^{\circ}$ N. J Geophys Res 100:3807-3827

Martinez F, Fryer P, Becker N (2000) Geophysical characteristics of the southern Mariana Trough, $11^{\circ} 50^{\prime} \mathrm{N}-13^{\circ} 40^{\prime} \mathrm{N}$. J Geophys Res 105:16591-16607

Matsuno T, Seama N, Evans R, Chave AD, Baba K, White A, Goto T, Heinson G, Boren G, Yoneda A, Utada H (2010) Upper mantle electrical resistivity structure beneath the central Mariana subduction system. Geochem Geophys Geosyst 11, Q09003. doi:10.1029/ 2010GC003101

Nakamura K, Toki T, Mochizuki N, Asada M, Ishibashi J, Nogi Y, Yoshikawa S, Okino K (2013) Discovery of a new hydrothermal vent site in the Southern Mariana Trough based on geophysical surveys using the AUV Urashima. Deep-Sea Research Part I 74:1-10

Sato T, Kennett BLN (2000) Two-dimensional inversion of refraction traveltimes by progressive model development. Geophys $\mathrm{J}$ Int 140:543-558

Smith WHF, Sandwell DT (1997) Global sea floor topography from satellite altimetry and ship depth soundings. Science 277:1956-1962

Takahashi N, Kodaira S, Tatsumi Y, Kaneda Y, Suyehiro K (2008) Structure and growth of the Izu-Bonin-Mariana arc crust: 1. Seismic constraint on crust and mantle structure of the Mariana arc-back-arc system. J Geophys Res 113:B01104. doi:10.1029/2007JB005120

Tolstoy M, Waldhauser F, Bohnenstiehl DR, Weekly RT, Kim WY (2008) Seismic identification of along-axis hydrothermal flow on the East Pacific Rise. Nature 451:181-184

Urabe T, Tsukada S (1991) A workstation-assisted processing system for waveform data from microearthquake networks (in Japanese). Abstracts of Spring Meeting of Seismological Society of Japan, $\mathrm{p} 70$

Urabe T, Ishibashi J, Maruyama A, Marumo K, Seama N, Utsumi M (2004) Discovery and drilling of on- and off-axis hydrothermal sites in backarc spreading center of southern Mariana Trough, western Pacific. Eos Trans AGU 85(47), Fall Meet Suppl, Abstract V44A-03

Vera EE, Mutter JC, Buhl P, Orcutt JA, Harding AJ, Kappus ME, Detrick RS, Brocher TM (1990) The structure of 0-My to 0.2-My old oceanic-crust at $9^{\circ} \mathrm{N}$ on the East Pacific Rise from expanded spread profiles. J Geophys Res 95:15529-15556

Wessel P, Smith WHF (1998) New improved version of Generic Mapping Tools released. EOS Trans AGU 79:579

Wheat CG, Fryer P, Hulme SM, Becker NC, Curtis A, Moyer C (2003) Hydrothermal venting in the southern most portion of the Mariana backarc spreading center at 12.57 degrees N. Eos Trans AGU 84 (46), Fall Meet Suppl, Abstract T32A-0920

Yamazaki T, Seama N, Okino K, Kitada K, Joshima M, Oda H, Naka J (2003) Spreading process of the northern Mariana Trough: riftingspreading transition at $22^{\circ} \mathrm{N}$. Geochem Geophys Geosyst 4(9): 1075 . doi: $10.1029 / 2002 \mathrm{GC} 000492$

Yoshikawa S, Okino K, Asada M (2012) Geomorphological variations at hydrothermal sites in the southern Mariana Trough: relationship between hydrothermal activity and topographic characteristics. Marine Geol 303-306:172-182

Zelt CA, Barton PJ (1998) Three-dimensional seismic refraction tomography: a comparison of two methods applied to data from the Faeroe Basin. J Geophys Res 103:7187-7210 